\title{
The Effects of Spirulina (Arthrospira platensis) Supplementation on Anthropometric Indices, Blood Pressure, Sleep Quality, Mental Health, Fatigue Status, and Quality of Life in Patients with Ulcerative Colitis: A Randomized, Double-blinded, Placebo-controlled Trial
}

\author{
sajjad Moradi ${ }^{1}$, Mehdi Zobeiri², Awat Feizi ${ }^{2}$, Cain C. T. Clark ${ }^{2}$, and Mohammad Hassan \\ Entezari $^{2}$ \\ ${ }^{1}$ Isfahan University of Medical Sciences \\ ${ }^{2}$ Affiliation not available
}

March 31, 2021

\begin{abstract}
Background: An emerging body of evidence has highlighted the protective role of spirulina in human health. Thus, we conducted a randomized controlled trial to discern the effects of spirulina supplementation on anthropometric indices, blood pressure, sleep quality, mood, fatigue status, and quality of life among ulcerative colitis patients. Methods: Eighty participants with ulcerative colitis were randomly allocated to receive, either, $1 \mathrm{~g} /$ day (two $500 \mathrm{mg}$ capsules) spirulina $(\mathrm{n}=40)$ or placebo $(\mathrm{n}=40)$, in a clinical trial for eight weeks. Dietary intake, physical activity, sleep quality, mental health, fatigue status, and quality, were assessed for each participant at baseline and trial cessation. Anthropometric indices and blood pressure were also assessed. Results: Seventy-three participants completed the intervention. Our results revealed that spirulina supplementation significantly reduced sleep disturbances $(\mathrm{p}=0.03)$, while no significant changes occurred in the sleep quality score or other sleep parameters, vs. the placebo group $(p>0.05)$. Furthermore, a significant reduction in stress score $(p=0.04)$ and increase in quality of life $(p=0.03)$ was detected, but not anxiety, depression, or fatigue scores $(\mathrm{p}>0.05)$. Additionally, anthropometric indices and blood pressure did not significantly change $(\mathrm{p}>0.05)$. Conclusion: An improved quality of life was observed among ulcerative colitis patients following spirulina supplementation, which could be attributed to improved sleep disturbance and stress status. Further clinical studies, with longer duration interventions and suitably powered sample sizes, are necessary to p elucidate the veracity of our findings.
\end{abstract}

\section{Hosted file}

Manuscript.pdf available at https://authorea.com/users/405092/articles/516117-the-effectsof-spirulina-arthrospira-platensis-supplementation-on-anthropometric-indices-bloodpressure-sleep-quality-mental-health-fatigue-status-and-quality-of-life-in-patientswith-ulcerative-colitis-a-randomized-double-blinded-placebo-controlled-trial

\section{Hosted file}

Figure 1.pdf available at https://authorea.com/users/405092/articles/516117-the-effectsof-spirulina-arthrospira-platensis-supplementation-on-anthropometric-indices-bloodpressure-sleep-quality-mental-health-fatigue-status-and-quality-of-life-in-patientswith-ulcerative-colitis-a-randomized-double-blinded-placebo-controlled-trial 


\section{Hosted file}

Table 1.pdf available at https://authorea.com/users/405092/articles/516117-the-effectsof-spirulina-arthrospira-platensis-supplementation-on-anthropometric-indices-bloodpressure-sleep-quality-mental-health-fatigue-status-and-quality-of-life-in-patientswith-ulcerative-colitis-a-randomized-double-blinded-placebo-controlled-trial

\section{Hosted file}

Table 2.pdf available at https://authorea.com/users/405092/articles/516117-the-effectsof-spirulina-arthrospira-platensis-supplementation-on-anthropometric-indices-bloodpressure-sleep-quality-mental-health-fatigue-status-and-quality-of-life-in-patientswith-ulcerative-colitis-a-randomized-double-blinded-placebo-controlled-trial

\section{Hosted file}

Table 3.pdf available at https://authorea.com/users/405092/articles/516117-the-effectsof-spirulina-arthrospira-platensis-supplementation-on-anthropometric-indices-bloodpressure-sleep-quality-mental-health-fatigue-status-and-quality-of-life-in-patientswith-ulcerative-colitis-a-randomized-double-blinded-placebo-controlled-trial 